\title{
Preliminary Investigation on Mechanical Properties of Polymer Coating Screws for the Future Fragility Fracture Fixation
}

\begin{abstract}
ALEXANDRU FILIP1, OANA VIOLA BADULESCU², PAUL DAN SIRBU ${ }^{1 *}$, BOGDAN VELICEASA ${ }^{1 *}$, BOGDAN PUHA ${ }^{1}$, IONUT ALIN PASCAL ${ }^{3}$, LIVIU ANDRUSCA ${ }^{3}$, STEFAN OPREA ${ }^{4}$, CRISTIANA FILIP ${ }^{5}$, OVIDIU ALEXA ${ }^{1}$

${ }^{1}$ Grigore T. Popa University of Medicine and Pharmacy, Faculty of Medicine, Department of Orthopedics and Traumatology Surgical Sciences (II), 16 Universitatii Str., 700115, Iasi, Romania

${ }^{2}$ Grigore T. Popa University of Medicine and Pharmacy, Faculty of Medicine, Department of Pathophysiology, Morfo-Functional Sciences (II), 16 Universitatii Str., 700115, lasi, Romania

${ }^{3}$ Gheorghe Asachi Technical University, Faculty of Mechanical Engineering, Department of Mechatronics and Robotics, 51 Profesor Dimitrie Mangeron Blvd., 700050, lasi, Romania

${ }^{4}$ Institute of Macromolecular Chemistry Petru Poni, Department of Polyadition and Photochemistry, 41A Grigore Ghica Voda Alley, 700487, Iasi, Romania

${ }^{5}$ Grigore T. Popa University of Medicine and Pharmacy, Faculty of Medicine, Department of Biochemistry, Morpho-functional Sciences (II), 16 Universitatii Str., 700115, lasi, Romania

Bone fracture fixation uses both consecrated materials, such as metals/metal alloys, as well as synthetic materials. Synthetic materials are extremely versatile in terms of simulating biological structures, biocompatibility and, in some cases, avoid the subsequent interventions for removing the prosthetic material. Fixing an osteoporotic fracture presents major risks of failure due mainly to the bone fragility. To reduce the risk of failure, prosthetic materials have been improved with various cements. The purpose of the current study was to assess the mechanical properties of different orthopedic screws covered with a new polyurethane acrylate polymer (PUA) in order to improve the stability of the screw for the subsequent fixation of the fragility fracture. To test the efficiency of the new polymer, the breaking/fracture strength of the orthopedic screws coated with PUA was evaluated, in comparison with the screws without coating material. Our data shows that tested PUA improves the bond between the screw and bone. We estimate that the effect obtained is caused by the partial damping of the loading force due to the elastic component of the polymer.
\end{abstract}

Keywords: polyurethane acrylate, osteoporotic fixation, fragility fracture

Osteoporosis is a disease with a high incidence that incapacitates the patients by decreasing the quality of life while being an economic burden. The most serious consequence of this condition is the risk of a fracture. The most common osteoporosis fractures, also named fragility fracture, are wrist, vertebral, hip fractures [1] and, as the life expectancy rises, the fragility fractures of the pelvis (FFP). An important risk factor for osteoporosis are glucocorticoids the standard first line treatment for immune thrombocytopenia [2]. The main problem in fixing the osteoporotic fracture is the fragility of the bone that affects the stability of the implanted devices. For this reason, there had been tried different ways to improve the stability of the implanted devices by using different types of cement [3]. Although most studies [4] showed that cement augmentation improves the screw fixation strength they exhibit a number of shortcomings: mismatch in stiffness between the cement and the contiguous bone, necrosis, thrombosis [5]. Therefore, there is still a great demand for new materials capable of improving the fixation strength especially for the osteoporotic bone. Currently, many synthetic materials, such as polymers, are in medical use: polyethylene, polyacrylate, polyurethanes (PU) [6]. Among all, we focus on polyurethane due to its high versatility that allows the simulation of human bone structure. The structural versatility of PU can be easily achieved by manipulating its composition through chemical reactions [7-10]. Conventional polyurethanes are generally obtained from poly-isocyanates, polyols and chain extenders. One of the raw materials used, aromatic isocyanates, causes serious health problems through degradation products (aromatic amines, carcinogens) when are introduced into the human body [11, 12]. For this reason, it was necessary to develop alternative methods for the polyurethane's synthesis. Particular attention was paid to obtain nonisocyanate polyurethanes such poly hydroxy-urethanes based on multicycle carbonates and aliphatic amines [ 13 , 14]. This type of polyurethanes also named polyurethanes acrylates (PUA) are highly hydrophilic and elastic. It contains a) a PU part that confers elasticity able to absorb some of the loading forces, b) an acrylate part, already used in dental prosthesis due to its strength, and c) a hydrophilic part which allows the compatibility to the biological tissue. The aim of the study was to assess the mechanical properties of different orthopedic screws covered with the new polyurethane acrylate polymer in order to improve the stability of the screw. To test the efficiency of the new polymer, the resistance of orthopedic screws covered with PUA was evaluated in comparison with screws without coating material when they were fixed on samples that simulate the osteoporotic bone. The study envisages the future use of the augmented screw for the fixation fragility fracture of the pelvis.

\section{Experimental part}

The experiment contains two phases: first the synthesis of the acrylate polyurethane polymer and second its mechanical testing following its application on different 
types of orthopedic screws used to fix artificial osteoporotic bone.

Polymer synthesis. The polymeric material used in this study is a new type of polyurethane PUA, synthesized at the Institute of Macromolecular Chemistry Petru Poni, Iasi, Department of Polyaddition and Photochemistry. The PUA has hydrophilicity and high elasticity, bio-compatibility, lack of toxicity, mechanical resistance butalso a certain degree of elasticity. PUA synthesis has the big advantage of using non-toxic raw materials: amines, ethylene carbonate, acrylic acids and water as a solvent [13]. The structure of macromolecular chain allows the grafting of $\mathrm{OH}$ terminal groups thus facilitating the use of water as a solvent in a non-toxic synthesis process [13]. The urethane groups can form hydrogen bonds with differentother chemical groups, thus favoring the physical grip on certain surfaces. Another advantage of PUA is the low economic cost due to the mechanism of the polymerization that can take place at ambient temperature. The urethane group was obtained by the analogous polymer reaction between cyclepolycarbonate (fig. 1.a) and several types of diamines (fig. 1.b) [13-17]. The obtained products were subjected to the condensation reaction with acrylic and methacrylic acid, resulting in a series of vinyl monomers containing urethanes groups whose structures are shown (fig. 2: A, B, C).<smiles>O=C(O)OCCCCCCCCOC(=O)O</smiles>

Diamine

(b)

$$
\mathrm{H}_{2} \mathrm{~N}-\left(\mathrm{CH}_{2}\right)_{n} \cdot \mathrm{NH}_{2} \quad \mathrm{n}=2 ; 3 ; 5 ; 6
$$

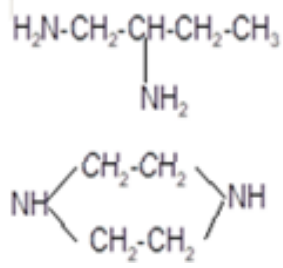

Fig.1. Structures of compounds used for the urethane groups synthesis
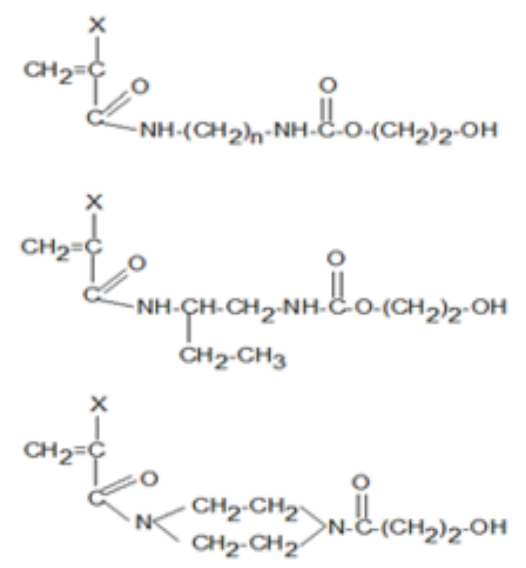

Fig.2.Vinyl monomers structures containing urethane groups

The vinyl monomers obtained, $A, B, C$ were subjected to polymerization in the presence of $\mathrm{K}_{2} \mathrm{~S}_{2} \mathrm{O}_{8}$, at low temperatures between $20-40^{\circ} \mathrm{C}$, resulting polymers with concentrations in dry matter 30-50\% and viscosities ranging between $40000-355000 \mathrm{cP}$ at $20^{\circ} \mathrm{C}$. The structure of the vinyl monomer selected for polymerization $(A)$, where $\mathrm{X}=\mathrm{H}$, is presented (fig. 3 ). The structure of the polymer resulted, named polyurethane acrylate polymer, is presented (fig. 4).<smiles>CCOOCNCCOC(=O)OCCO</smiles>

Fig. 3. The structure of

the vinyl monomer selected for

polymerization

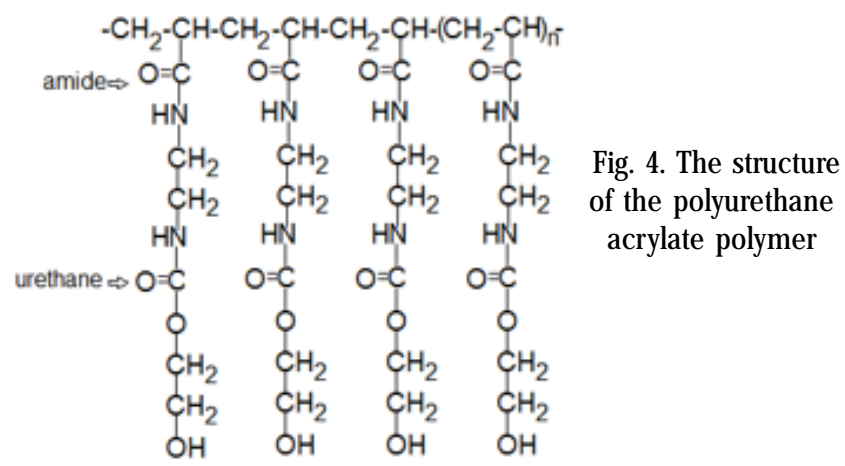

The structure of the polymer was confirmed by the spectra IR and ${ }^{1} \mathrm{H} R M N$. In the IR spectrometry the polymer shows the following characteristic bands: $3300 \mathrm{~cm}^{-1}(\mathrm{NH}$; $\mathrm{OH}$ hydrogen bridges); $2968 \mathrm{~cm}^{-1}\left(\mathrm{CH}_{\delta} \delta\right.$ as $) ; 1695 \mathrm{~cm}^{-1}$ ( $>\mathrm{C}=0$; amide band I); $1540 \mathrm{~cm}^{-1}$ ( $\mathrm{NH}^{2}$ and $\mathrm{C}-\mathrm{N}$ amide band II; $1448 \mathrm{~cm}^{-1}$ and $1395 \mathrm{~cm}^{-1}\left(>\mathrm{CH}_{2}\right) ; 1325 \mathrm{~cm}^{-1}$ and $1255 \mathrm{~cm}^{-1}\left(>\mathrm{C}-\mathrm{N}\right.$ and $\mathrm{NH}$ amide band ${ }^{2} \mathrm{Il}$. In the ${ }^{1} \mathrm{H}$ NMR spectrometry the polymer shows the following characteristic bands: 1,7 and $2 \mathrm{ppm}$ protons from $-\mathrm{CH}_{2}^{-}$ $\mathrm{CH}<; 3,2 ; 3,3 ; 3,4 ; 3,5$ ppm protons from $\mathrm{OCONH}_{-} \mathrm{CH}_{2}^{2}$ $\mathrm{CH}_{2}-\mathrm{N}<; 3,8 ; 4 \mathrm{ppm}$ protons from $\mathrm{OCO}-\mathrm{CH}_{2}-\mathrm{CH}_{2}-\mathrm{OH} ; 7,8$ ppm protons from urethane $\mathrm{NH}$ group.

\section{Mechanical tests}

The mechanical tests evaluated the behavior of the orthopedic titanium screws covered with a polymeric film that were fixed on synthetic bone samples. Synthetic samples (Sawbones-SKU:1522-09) simulating osteoporotic bone were 7.5 PCF cell polyurethane foam blocks (size $40 \mathrm{~mm} \times 130 \mathrm{~mm} \times 180 \mathrm{~mm}$ and density $0.16 \mathrm{~g}$ / cm3 similar to osteoporotic density). The titanium screws (Biomatrix) used have different diameters: 4.5 cortical screw, 6.5 malleolar screw and 6.5 cancellous screw, length $60-70 \mathrm{~mm}$. The polymer applied on the surface of the screws was left to stand up to $24 \mathrm{~h}$ to complete the polymerization reaction. Both uncoated and PUA coated screws were subjected to a tensile force applied by a static testing machine (WDW-50E) using a speed of $1 \mathrm{~mm} / \mathrm{min}$. The tensile forces applied to cause fracture and displacements were recorded by a specialized WDW Universal Testing Machine Measure \& Control System program.

\section{Results and discussions}

The selected acrylic urethane monomer has the advantage of low temperature polymerization. Left at ambient temperature, in a free atmosphere, the monomer will polymerize. The initiation of polymerization is catalyzed by the action of light and oxygen. Oxygen reacts with the double vinyl bond and leads to hydroperoxides, which, under 


\begin{tabular}{|c|c|c|c|c|}
\hline & \multicolumn{2}{|c|}{ Without PUA coating } & \multicolumn{2}{c|}{ With PUA coating } \\
\hline $\begin{array}{c}\text { thread diameter } \\
(\mathrm{mm})\end{array}$ & $\begin{array}{c}\text { Maximum force } \\
(\mathrm{N})\end{array}$ & $\begin{array}{c}\text { Displacement } \\
(\mathrm{mm})\end{array}$ & Maximum force (N) & Displacement (mm) \\
\hline $\begin{array}{c}4.5 \text { cortical } \\
\text { screw }\end{array}$ & $1.040 \pm 0.01$ & $4.995 \pm 0.103$ & $1.085 \pm 0.005$ & $11.016 \pm 0.003$ \\
\hline $\begin{array}{c}6.5 \text { malleolar } \\
\text { screw }\end{array}$ & $1.060 \pm 0.012$ & $7.088 \pm 0.016$ & $1.100 \pm 0.014$ & $10.829 \pm 0.05$ \\
\hline $\begin{array}{c}6.5 \text { cancellous } \\
\text { screw }\end{array}$ & $1.150 \pm 0.005$ & $6.973 \pm 0.084$ & $1.280 \pm 0.016$ & $12.449 \pm 0.173$ \\
\hline
\end{tabular}

Table 1

MAXIMUM TENSILE

FORCES AND

DISPLACEMENTS

DETERMINED FOR

THE SCREWS the action of light radiation or thermal effect, break down into free radicals that initiate the polymerization reaction. The ability to initiate the reaction by the excited urethane portion is confirmed by the UV spectra of the acrylic monomer which indicates the ability of the monomer to absorb radiation with energy of $128.25 \mathrm{kcal} / \mathrm{mol}$ sufficient to trigger the polymerization reaction. The resulting polymer is adhesive to any material, the adhesion being about $0.2-$ $0.3 \mathrm{~kg} / \mathrm{cm}^{2}$. In aqueous environmentPUA has high swelling capacity, which, in vivo, would allow access of calcium and phosphate thus favoring bone mineralization.

In the particular case of the pelvis fracture, the main stress is the compression stress, but tensile testing is one of the most accurate methods for measuring bone properties $[18,19]$. J oint behavior was evaluated in terms of maximum tensile forces and displacements [20]. Results are presented in table 1.

The obtained data show that after the PUA application the mechanical behavior of the joint between the coated screw and the bone have been improved. The increased resistance to loading, noticed in the coated screws, may be due to the capacity of partial takeover of the tensile force due to the elastic properties of the polymer. Under the action of the maximum force the deformation presents significant increases for all screws covered with polymer compared to those not covered. This indicates that the structure suffers a greater deformation for a long time, thus breaking up later. This behavior can be attributed to the elastic character of the polymer which dampens part of the applied force. At the same time, the polymer coating seems to ensure a more efficient transition between the metal surface and the artificial bone structure [21, 22], improving the cohesion of the entire prosthetic device. In the particular case of FFP, preoperative information, such as implant position, and screw length brought by modern technology [23] can be of real value in improving both the approach and the result in the surgical treatment of these fractures.

\section{Conclusions}

Improvement of prosthetic elements, in the particular case of fragility fractures, can be achieved by using synthetic materials whose characteristics can be manipulated to ensure a better stability of the prosthesis devices. The polymer coating improves the bond between screw and bone which augments the fracture fixation. This difference is probably due to a better adhesion between the metal device and the contiguous testing blocks or to the partially elastic feature of the polymer. The improved adhesion is supposed to absorb some of applied force. The hydrophilic polymer favors a good compatibility with the biological environment and probably a good adhesion in vivo. Even though the study is a preliminary one, the main limitation is the use of the synthetic bone model instead of the real bone.

\section{References}

1.***https://www.ncbi.nlm.nih.gov/pmc/articles/PMC4518640/CR1GOLDHAHN, J., SUHM, N., GOLDHAHN, S., BLAUTH, M, HANSON, B., Influence of osteoporosis on fracture fixation-a systematic literature review., Osteoporos Int., 19, nr.6, 2008,p.761

2.MOCANU, M., BADESCU, M., HANCIANU, M., BADULESCU,O.V., Role of Immunochemical Detection Methods in the Diagnosis of Immune Thrombocytopenic Purpura, Rev. Chim. (Bucharest), 66, no. 7, 2015, p. $997-1000$

3.JUVONEN,T.,NUUTINEN, J.P.,KOISTINEN,A.P.,KROGER,H.,LAPPALAINEN,R., Biomechanical evaluation of bone screw fixation with a novel bone cement,Biomed Eng Online, 14, nr.1, 2015, p.74

4.WAHNERT, D., HOFMANN-FLIRI, L., SCHWIEGER, K., BRIANZA, S., RASCHKE, M.J., WINDOLF, M., Cement augmentation of lag screws: an investigation on biomechanical advantages, Archives of orthopaedic and trauma surgery,133,nr.3, 2013, p.373

5.LIU, D., LEI, W., WU, Z.X., GAO, M.X., WAN, S.Y., FU, S.C.,SHI,L., Augmentation of pedicle screw stability with calcium sulfate cement in osteoporotic sheep: biomechanical and screw-bone interfacial evaluation, J Spinal Disord Tech, 24, nr.4, 2011, p.235

6.SIRBU, P.D., TUDOR, R., BEREA, G., SCRIPCARU, A., CIUBARA, B., BADULESCU, O.V., Bipolar Polyethylene Radial Head Artroplasty in Posttraumatic Unstable Elbows. Prosthetic design and clinical results, Mat. Plast,,54, no. 2, 2017, p. 298-301.

7.HE, W., BENSON, R., Polymeric biomaterials, Applied Plastics Engineering Handbook. William Andrew Publishing, 2017, p. 145

8.ZIVIC, F., GRUJ OVIC, N., PELLICER, E., SORT, J., MITROVIC, S., ADAMOVIC, D., VULOVIC, M. F., Biodegradable Metals as Biomaterials for Clinical Practice: Iron-Based Materials, Biomaterials in Clinical Practice, Springer, Cham, 2018, p. 225

9.MAURYA D.S., KURMVANSHI S.K., MOHANTY S., NAYAK S.K., A Review on Acrylate-Terminated Urethane Oligomers and Polymers: Synthesis and Applications, Polymer-Plastic Technology and Engineering, 57, nr. 7, 2018, p.625

10.RAHMATI, M., PENNISI, C. P., BUDD, E., MOBASHERI, A., \& MOZAFARI, Biomaterials for Regenerative Medicine: Historical Perspectives and Current Trends, Cell Biology and Translational Medicine, 4, 2018, p. 1 11.ROKICKI,R., PARZUCHOWSKI,P.G., MAZUREK, M., Non isocyanate polyurethanes: synthesis, properties, and applications, Polym. Adv. Technol, 26, nr.7, 2015, p. 707

12.BADESCU, L, BADULESCU, O., BADESCU, M., CIOCOIU, M., Natural polyphenols improve the dislipidemy and eye complications in the experimental diabetes mellitus. Romanian Biotechnological Letters, 2012, 17(4):7397-7407.

13.CIOBANU C. FARCAS A. Brevet Romania 93572 (1987).

14.OPREA S., CIOBANU C., NASTASE 0.I. Brevet România 111465, (1996)

15.NOHRA, B., CANDY,L., BLANCO,J.F., GUERIN, C., RAOUL, Y., MOULOUNGUI, Z., From petrochemical polyurethanes to biobased polyhydroxyurethanes, Macromolecules, 46, nr. 10, 2013, p. 3771 
16.BOBBINK, F.D., VAN MUYDEN, A.P., DYSON, P.J., Enrouteto CO2containing renewable materials:catalytic synthesis of polycarbonates andnon-isocyanate polyhydroxyurethanes derivedfrom cyclic carbonates, Chem. Commun., 55,nr.10, 2019, p.1360

17.MAISONNEUVE,L., LAMARZELLE, O., RIX,E., GRAU, E., CRAMAIL, $\mathrm{H}$., Isocyanate-free routes to polyurethanes and poly (hydroxy urethane) s, Chem. Rev., 115, nr.22, 2015, p. 12407

18.ZANETTI, E.M., BIGNARDI, C., AUDENINO,A.L., Human pelvis loading rig for static and dynamic stress analysis, Acta of Bioengineering and Biomechanics, 14, nr.2, 2012, p.61

19.KHAN, S. N.; WARKHEDKAR, R. M.; SHYAM, A. K., Human Bone strength Evaluation through different Mechanical Tests,International Journal of Current Engineering and Technology, 2,2014, p.539
20.BANKOFF, ADP., Biomechanical Characteristics of the Bone, Human Musculoskeletal Biomechanics, InTech, Goswami T., Editor, Rijeka Croatia, 2012, p. 61

21.SRIVASTA A., AGARWAL D., MISTRY S., SINGH J ., UV curable polyurethane acrylate coatings for metal surfaces, Pigment \& Resin Technology, 37 nr. 4, 2008, p. 217

22.BORZAN, C. S. M., DUDESCU, M. C., CECLAN, V., TRIF, A., RIDZON, M., BERCE, P., The Advantages of High-density Polymer CAD/CAM Interim Restorations in Oral Implantology, Mat. Plast, 53, no.1, 2016, p.1

23.MALANCEA, R.I., GAVRILIUC, E.R., VELICEASA, B., PUHA, B., POPESCU, D., ALEXA, O., Methodology of Three-dimensional Printing in Acetabular Fractures,Mat.Plast., 54, no.3, 2017, p. 513

$\overline{\text { Manuscript received: } 6.07 .2019}$ 